\title{
Influence of Differences in Materials, the Dimensions and Scape of the Material Undergoing Drying on the Drying Process
}

\author{
Radivoje M. Topić ${ }^{1, *}$, Goran R. Topić ${ }^{2}$, Jelena R. Topić ${ }^{3}$ \\ ${ }^{1}$ Faculty of Mechanical Engineering University of Belgrade, Serbia \\ ${ }^{2}$ Serbiagas, Belgrade, Serbia \\ ${ }^{3}$ Energoprojekt, Belgrade, Serbia \\ *Corresponding author: rtopic@mas.bg.ac.rs
}

Received December 09, 2013; Revised March 18, 2014; Accepted March 22, 2014

\begin{abstract}
In this paper an original solution of a small capacity infrared dryer for home use for drying biological material is given. The dryer is transportable, with small dimensions and is characterized by a cylindrically shaped drying chamber. An infrared heater is placed in the center of the dryer. Five vertical cylinders with perforated walls for placing material in the drying process are positioned around the heater. Due to the construction of the mechanical transporter in the drying process the cylinders rotate around their vertical axis, thus leading to more uniform heating of the material volume and a stage radiation regime. The dryer dimensions are: maximal width $320 \mathrm{~mm}$ and height $450 \mathrm{~mm}$. The dryer capacity of moist material is around 2, $5 \mathrm{~kg}$. In the paper has defined the mathematical models for analysis of the influence of the material types, shape and dimensions of the surface undergoing on the drying process. Based on analytical equation, defined of the mathematical models, and drying kinetics were defined based on experimental results drying process of apples in infrared and convective dryer small capacity, gives the graphical dependence and corresponding analysis.
\end{abstract}

Keywords: infrared dryer, convective dryer, small capacity, drying

Cite This Article: Radivoje M. Topić, Goran R. Topić, and Jelena R. Topić, "Influence of Differences in Materials, the Dimensions and Scape of the Material Undergoing Drying on the Drying Process.” American Journal of Food Science and Technology, vol. 2, no. 2 (2014): 62-66. doi: 10.12691/ajfst-2-2-3.

\section{Introduction}

Infrared drying has been investigated as a potential method for obtaining high quality dried foodstuffs, including fruits, vegetables and grains. However, infrared drying and drying kinetics has been reported till now. Therefore, the scientists at Faculty of Engineering, Department of Chemical Engineering, Firat University, Turkey conducted studies with there objectives [1]. Presently, infrared (IR) drying, which is the most efficient form of electromagnetic radiation for heat transfer, has been gaining interest in the agro-industry because of its high thermal efficiency, fast heating response time, and direct absorbability by the material. This drying technology has appeared as one of the potential alternatives to the traditional heating methods for obtaining high-quality dried food, because of several intrinsic advantages, such as simplicity of the required equipment, easy adaptation of the IR heating with conductive, convective, and microwave heating, and significant energy conservation [2]. Bearing in mind the advantages of the infrared radiation based drying process and the set - backs of the conventional solutions, a new design solution of the dryer is defined. Wet material intended for drying represent gray bodies from the radiation aspect. The analysis of the drying process presents the issue of the suitability of use of the interrupted radiation of the humid material, compared to the combination of infrared heating of the material with air-cooling, or to the aging period. The maximum drying intensity and the required quality of the material is achieved only when the spectral characteristics of the radiation source are coordinated with the optical characteristics of the dried material.

\section{Dryer Design Solution}

Infrared, ecological, universal, portable dryer intended for drying biological material by means of infrared radiation, [3,5,6,7] for household use is shown on Figure 1. The drying chamber has a circular cross-section with perforated cylinders with trays for the dried material distributed vertically along the circumference. Inside the chamber, in the center, the radiation system, that is an infrared electrical heater, is located. The cover, with channels for placing the upper cylinder supports is located at the top of the chamber, while the cylinder bottoms are in direct connection with the rotation system. The drying chamber has a removable lining, which has holes near the 
bottom and the top, providing for the natural draught. The regulation system enables the change of the surface thermal power of the radiation source, depending on the type of dried material.

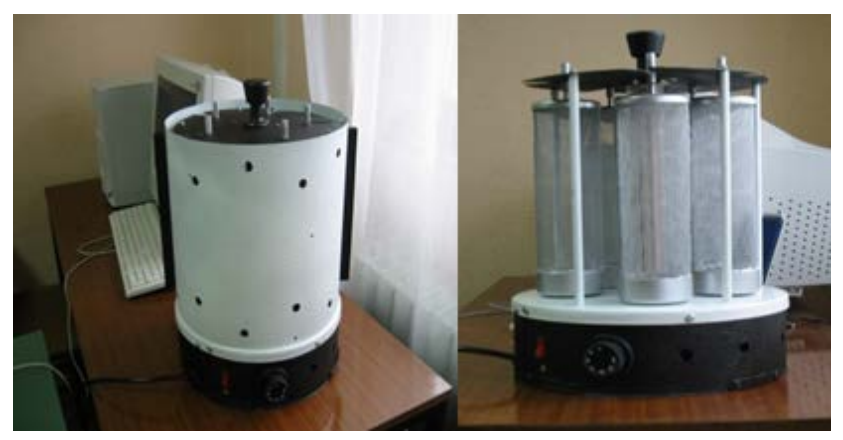

Figure 1. Infrared, ecological, universal, portable dryer based on indirect application of electricity as the heat source

In Figure 2, Presents cylinder storage space and a system for spinning cylinders.

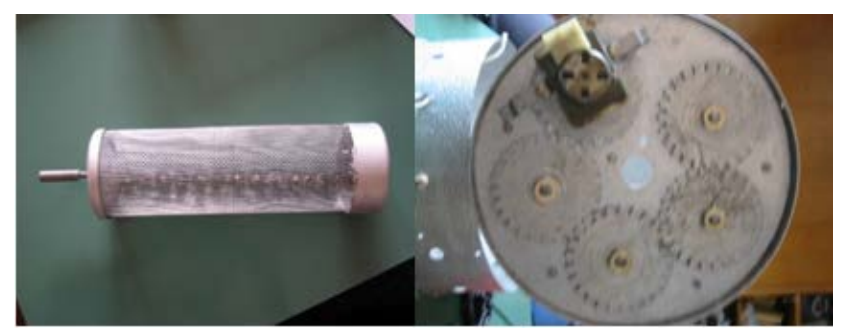

Figure 2. Cylinder storage space and a system for spinning cylinders

\subsection{Optimization of the Drying Process and Dryer Solution}

It is possible to analyze the drying process and dryer solution from the viewpoint of parameters of the material, heat source and drying chamber.

2.1.1. Influence of Differences in Materials, the Dimension and Shape of the Material Under Going Drying on the Evaporation Surface [3]

In Figure 3, presents a method of cutting material.
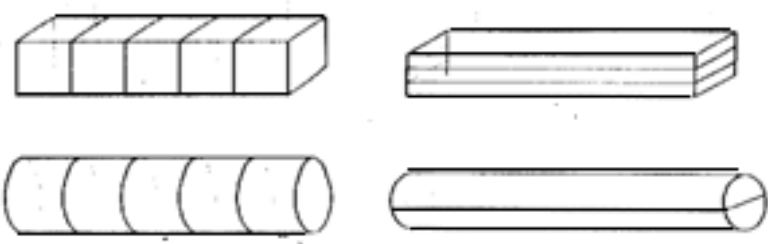

Figure 3. Presents a method of cutting material

As far as the shape and dimension of the material undergoing drying is concerned this analysis started with a particle (unit) volume with equal volume and mass of parallelepiped shaped particles with the purpose of defining particle surfaces of materials participating in the drying process.

The number of parallelepiped shaped particles in $1 \mathrm{~kg}$ of a material undergoing drying is:

$$
n_{p}=\frac{1}{m_{p}} .
$$

The surface of one particle (unit) of the material determined via side a and side parameter $n_{i}$ is:

$$
F_{p 1}=\frac{2+2 \cdot n_{i}^{2}+2 \cdot n_{i}}{n_{i}} \cdot a_{p}{ }^{2} .
$$

Based on equations for particle volume, particle mass

$$
F_{p}=\frac{2+2 \cdot n_{i}^{2}+2 \cdot n_{i}}{n_{i} \cdot \rho_{m} \cdot a_{p}} .
$$

Multiplication of this equation with material mass $m$ gives the total particle surface of $a_{p}$ material $F_{m}$ in the material mass $m$.

In the case when material units (particles) in the form of cubes and rectangular prisms of the same cross sections are compared, the surface equation is:

$$
F_{p}=\left(2+4 \cdot n_{i}\right) \cdot a_{p}
$$

The particle surface in $1 \mathrm{~kg}$ of a material is then

$$
F_{p}=\frac{\left(2+4 \cdot n_{i}\right)}{n_{i} \cdot \rho_{m} \cdot a_{p}} .
$$

In the case of cutting a material unit in the form of a parallelepiped the surface equation is:

$$
F_{p}=4 \cdot a_{p} \cdot l_{p}+2 \cdot a_{p}^{2} \cdot \frac{l_{p}}{b},
$$

and in the case of tearing or lengthwise cutting:

$$
F_{p}=2 \cdot a_{p}^{2}+2 \cdot a_{p} \cdot l_{p}+2 \cdot \frac{a_{p}^{2}}{b} \cdot l_{p},
$$

where $a_{p}$ is the base side and $\mathrm{b}$ is the length or side of the base of the parallelepiped obtained

The surface ratio defined as: in the case of cutting:

$$
\frac{F_{p}}{F_{p b}}=\frac{4 \cdot a_{p} \cdot l_{p}+2 \cdot a_{p}^{2} \cdot \frac{l_{p}}{b}}{2 \cdot a_{p}^{2}+4 \cdot a_{p} \cdot l_{p}},
$$

tearing:

$$
\frac{F_{p}}{F_{p b}}=\frac{2 \cdot a_{p}^{2}+2 \cdot a_{p} \cdot l_{p}+2 \cdot \frac{a_{p}^{2}}{b} \cdot l_{p}}{2 \cdot a_{p}^{2}+4 \cdot a_{p} \cdot l_{p}}
$$

enables determination of changes in material surface values.

A similar analysis is possible for cylindrically shaped material units. Due to irregular shapes and dimensions of particles it is necessary to introduce shape factors and variables that include these influences.

Equation (2) enables a detailed analysis of the influence of the material type, shape and dimension of particles (units) on the drying process. If a first derivative is determined of the expression for particle surface for the side parameter the extreme value of $n=1$ is obtained, corresponding to a cube, indicating the smallest surface value. It is obvious that for values of the side parameter $n_{i}=1$ it is a cube, and for $0<n_{i}<1$ and $n_{i}>1$ it is a rectangular prism. The influence of differences in materials is analyzed through a material density $\rho_{m}$, 
which changes in the range between 700 and $1300 \mathrm{~kg} / \mathrm{m}^{3}$. The particle shape is analyzed through cubic and rectangular prism shapes, while the influence of particle density is analyzed through changes of side values of the rectangular prism side $a_{\mathrm{p}}$.

The diagram on Figure 4, according to equation (2) gives the dependence of the evaporation surface of differently shaped particles (cube for $\mathrm{n}_{\mathrm{i}}=1$ and rectangular prism for $n_{i}=2 a_{p}$ ) on material density for different values of side $a_{\mathrm{p}}$. These dependencies show that increase of the materials surface is higher in the region of smaller densities and that this increase grows rapidly with decrease of the The diagram on Figure 5 also according to equation (2) shows the change of particle surface of the material with constant side a in dependence on the material type (material density) for different values of the side parameter $n_{i}$. A higher increase of the particle surfaces of the material in regions of smaller density values and for higher values of the side parameter $n_{i}$ is obvious.

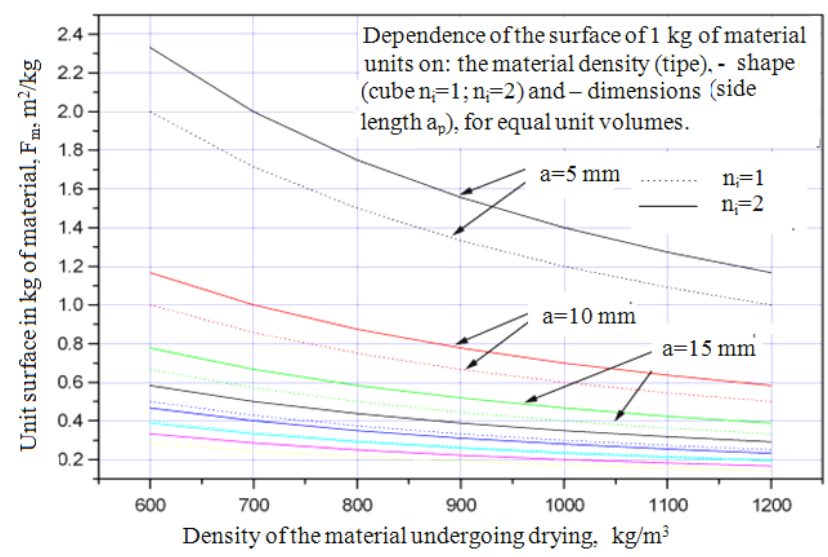

Figure 4. Change of the evaporation surface of the material in dependence on the material type and dimensions

\section{Experimental Research}

The purpose of experimental research is investigation of a new dryer solution with the purpose of defining a temperature field in the drying chamber space around the infrared dryer and defining the drying kinetics for different experimental conditions.

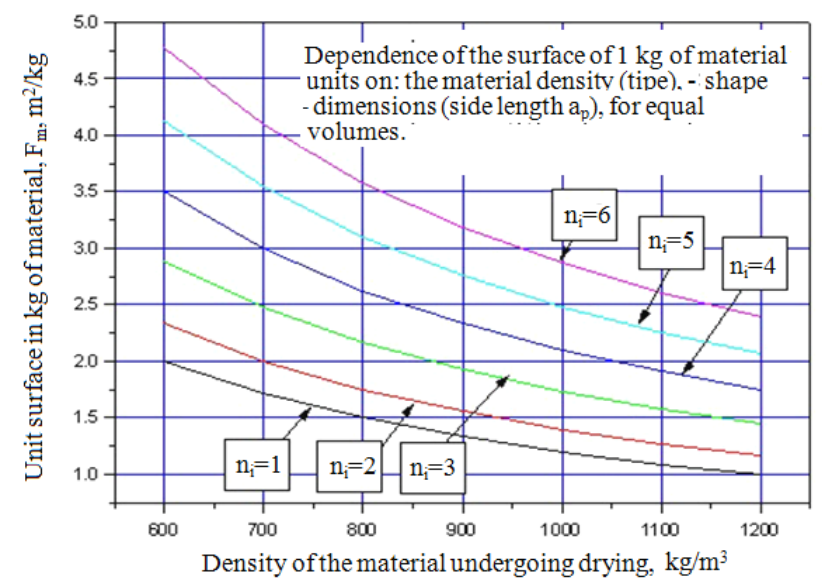

Figure 5. Change in the evaporation surface of a material in dependence on the material type and shape

\subsection{Defining the Temperature Field Around the Infrared Heater}

Measurements were performed on an installation consisting of an infrared dryer, necessary measuring instruments and a device for changing heater power.

The temperature was measured at the distance of $r_{i}=$ var. for different heater power values. During measurements the heater power was changed by varying the voltage with a rheostat. The influence of the value of thermal strength, drying chamber covering and thermometer covering on the temperature field, change on temperature along the chamber radius around the infrared heater is given in Figure 6 . The influence of the protective covering of the drying chamber on changing trends and temperature values are shown by curves (1) and (2). Curves (2) and (3) show the influence of the radiation effect (heat source) on

Temperature values in the drying chamber. It is obvious, that for given conditions, the influence of radiation is completely lost for $d_{m}>12 \mathrm{~cm}$. Curves (3) and (4) show the influence of power (voltage) of the infrared heater on temperature values, temperature values in the drying chamber. It is obvious, that for given conditions, the influence of radiation is completely lost for $d_{m}>12 \mathrm{~cm}$. Curves (3) and (4) show the influence of power (voltage) of the infrared heater on temperature values.

\subsection{Definition of Drying Kinetics and Drying Curves}

Analytical or graphical definition of drying curves is possible by calculating moisture values at certain moments according to expression:

$$
u_{i}=\frac{m_{i}-m_{a d m}}{m_{a d m}} .
$$

The influence of the drying method and material dimensions is given in the diagram on Figure 7. Figure 7 contains drying curves defined based on experimental data of the drying process of apple samples:

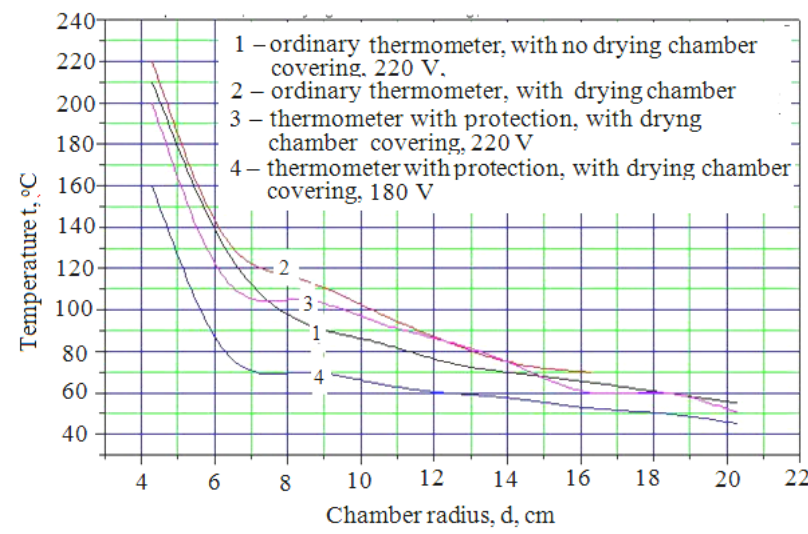

Figure 6. Dependence of temperature on the radius under varying conditions

with an infrared dryer with sides $\mathrm{a}_{\mathrm{p}}=10 \mathrm{~mm}$ and conditional temperature value of $110^{\circ} \mathrm{C}$ (temperature at the measurement-regulation point) - curve (1); convection mini cube dryer with sides $a_{p}=10 \mathrm{~mm}$ - curve (2) and slices $5 \mathrm{~mm}$ thick, with temperatures of the drying agent of $\mathrm{t}=70^{\circ} \mathrm{C}$ - curve (3). 
The drying curve (1) can be described analytically with the dependence:

$$
u=e^{\left(a+b \cdot \tau^{1,5}\right)}
$$

and coefficient values of $a=2,3642495:$ and $b=-0,0016591081$; standard deviation $\sigma=0,193$ and correlation degree $r=0,997$.

Differentiating the expression for absolute moisture gives the drying rate expression of the form:

$$
N=-1,5 \cdot b \cdot \tau^{0,5} \cdot e^{\left(a+b \cdot \tau^{1,5}\right)}
$$

The influence of material type, form, dimension and drying method is given in Figure 7, with drying curves (1) to (8) for analogous drying regimes. Curves of drying kinetics in Figure 7 were obtained by simultaneous drying of apple charges (cylinder filling about $402 \mathrm{~g}$ ) of different shapes (in 3 cylinders: cubes, slices and rectangular prisms) and carrot charges with different slice thick nesses (in 2 cylinders).

Cube and slice apple charges and carrot slice charges were dried in convection dryer. Curve (1) corresponds to the drying process of apple cubes with sides $a_{p}=10 \mathrm{~mm}$ in an infrared dryer, while curve (2) corresponds to drying in a mini convective dryer. Curve (3) corresponds to the drying process of apple slices $5 \mathrm{~mm}$ thick in an infrared dryer, while curve (4) corresponds to the drying process in a mini convective dryer. Curves (1) and (3) show the influence of the material (apple) shape on the drying process in an infrared dryer. It is obvious that slices dry faster than cubes. There was less material in the shape of rectangular prisms (about $200 \mathrm{~g}$ ) as due to higher porosity and lower green density the same amount could not fit into the material cylinder during the drying process. Curve (5) represents the drying process of apple rectangular prisms with base $a_{p}=10 \mathrm{~mm}$ and length $\mathrm{l}_{\mathrm{p}}=30 \mathrm{~mm}$ in an infrared dryer. Curve (6) represents the drying process of apple slices $5 \mathrm{~mm}$ thick in a mini convective dryer, Stockli, Switzerland Figure 8, [8].

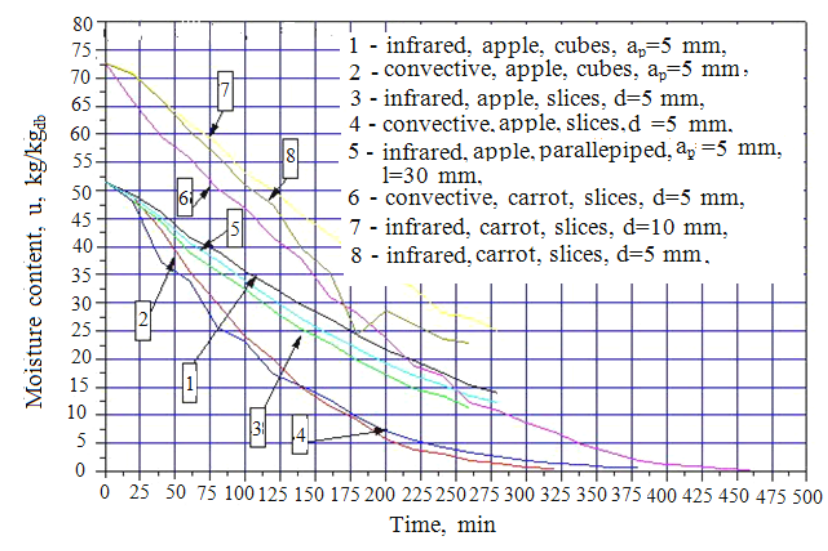

Figure 7. Curves of the drying kinetics of different materials in an infrared and mini convection dryer

Curves (7) and (8) represent the drying process of carrot slices $5 \mathrm{~mm}$ and $10 \mathrm{~mm}$ thick in an infrared dryer, respectively. They show the influence of slice thickness on the drying process. It should be mentioned that the capacity of the infrared dryer was for about $800 \mathrm{~g}$ higher than the capacity of the mini convection dryer. The proposed drying regimes for some materials will be given on the dryer lid.

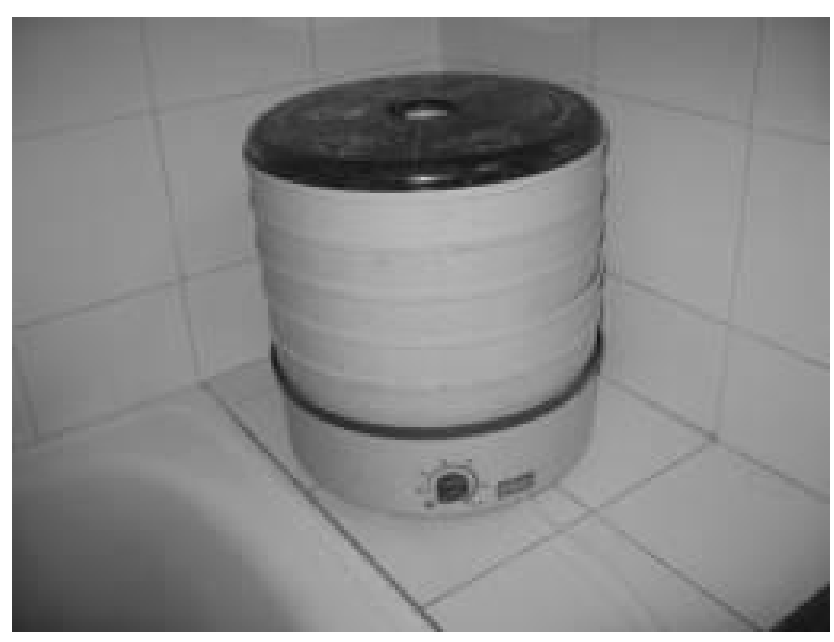

Figure 8. Mini cabinet, convection dryer Stockli, Switzerland [8]

\section{Conclusion}

The mathematical models defined enable broader optimization from the viewpoint of shape, dimension and type of material and definition of temperature fields. Based on experimental data the temperature field and drying kinetics defined speak of the performance and quality of the mini infrared dryer in comparison with the mini convection dryer. Working characteristics of the dryer solution are: possible operation in different locations as the device is transportable; uses infrared radiation based on indirect use of electric energy as a heat source; fast heating of the drying chamber; enables redirection of reflected radiation to the material undergoing drying; more even spatial temperature distribution; elimination of drying only one material surface; shorter drying time and smaller energy consumption in comparison with classical infrared dryers; possibility of drying different materials with varying shapes and dimensions (pieces, whole, bunch, etc.); multiple application (heater, grill, cooker); low investment costs; low driving costs; simple operation; does not pollute the environment.

\section{Notacion}

\begin{tabular}{|c|c|c|}
\hline $\mathrm{a}$ & side length, constant & $\mathrm{m}$ \\
\hline $\mathrm{b}$ & base length, constant & $\mathrm{m}$ \\
\hline $\mathrm{d}$ & diameter, stoutness & $\mathrm{m}$ \\
\hline $\mathrm{F}$ & surface & $\mathrm{m}$ \\
\hline $\mathrm{m}$ & mass & $\mathrm{kg}$ \\
\hline $\mathrm{n}$ & parameter & $\mathrm{K}$ \\
\hline $\mathrm{r}$ & correlation degree & ${ }^{\circ} \mathrm{C}$ \\
\hline $\mathrm{T}$ & absolute temperature & $\mathrm{kg} \mathrm{kg}^{-1}$ \\
\hline $\mathrm{t}$ & temperature & $\mathrm{s}$ \\
\hline $\mathrm{u}$ & moisture content (d. b.) & $\mathrm{kg} \mathrm{m}^{-3}$. \\
\hline \multicolumn{3}{|c|}{ Greek letters } \\
\hline$\tau$ & time & \\
\hline$\rho$ & density & \\
\hline$\sigma$ & standard deviation & \\
\hline \multicolumn{2}{|c|}{ Subscripts } \\
\hline $\mathrm{adm}$ & absolute dry material & \\
\hline $\mathrm{d} . \mathrm{b}$. & material, & \\
\hline $\mathrm{m}$ & particle, rectangular prism, & \\
\hline $\mathrm{p}$ & &
\end{tabular}




\section{References}

[1] Togrul H., Suitable drying model for infrared drying of carrot, Journal of Food Engineering, Volume 77, Issue 3. 2006, 100-110

[2] Juckamas Laohavanich, Thin layer drying model for gas-fired infrared drying of paddy, Songklanakarin J. Sci. Technol. 30 (3), 343-348, May - Jun. 2008

[3] Topić M. R., Development and advancement technology and solution for infrared drying biological materials based electrical energy as the heat source, project- NP EE 306 - 74 B, Belgrade, S\& MN. 2002

[4] Topić, M. R. Small capacity Mobile Dryers for Drying Biological Materials, Proceedings of the 13th International Drying Symposium, Vol. C. (2002), pp. 1504.
[5] Topić M. R, Topić R. G. Presentation of the design concept of an infrared small capacity dryer based on indirect use of electrical energy, Proceedings of the Processing, 203-211, Zrenjanin, S\& MN. 2003.

[6] Topić, M. R., Small capacity Mobile Dryers for Drying Biological Materials, Drying technology Vol. 21, no. 6, Dedicated to professor Chong-Wen Cao on the occasion of his $75 \mathrm{~h}$ birthday. 2003.

[7] Topić, M. R., Topić R. G. Presentation of the concept of a design of an infrared dryer, with a small capacity, based on indirect use of electrical energy and optimization of the drying process and solutions, European Drying Symposium, Heraklion, Crete, Greece. 2003.

[8] Mini convection dryer Stockli, Switzerland, 2003. 